\title{
Sustainable stormwater management tool at the neighbourhood scale
}

\author{
A. Romnée ${ }^{1}, \mathrm{~K}$. de Bondt ${ }^{2} \& \mathrm{~V}$. Mahaut ${ }^{3}$ \\ ${ }^{1}$ Architecture et Climat, Université catholique de Louvain, Belgium \\ ${ }^{2}$ Earth System Sciences, Vrije Universiteit Brussel, Belgium \\ ${ }^{3}$ École d'architecture, Université de Montréal, Canada
}

\begin{abstract}
As in most cities, the natural water cycle is disrupted in the Brussels-Capital Region (BCR) because of the large and still increasing soil waterproofing in private parcels and public spaces. Consequently, severe and recurrent floods occur in the whole region. Major public works, such as stormwater reservoirs and combined sewers have proven their limits to mitigate this increasing risk. The Brussels Environment agency asked to develop a tool, at the neighbourhood scale, to promote Best Management Practices (BMPs) in the public space: the QUADEAU tool. This sustainable stormwater management tool evaluates the hydrological efficiency of a public space in a renovation or new urban project. The public space projected is modelled in the tool by characterizing all areas of the project, by creating the flow networks between these surfaces and by designing the BMPs used in network in the project. Then the tool calculates the total volumes of stormwater that percolate through the soil, evaporate, accumulate in the BMPs and finally flow into the outlet. The flow into the outlet has to match the hydrological thresholds determined in function of the total imperviousness of the neighbourhood, the type of project and the local hydrogeology. QUADEAU aims to be used for the predimensioning and for the optimization of all specific characteristics of the BMPs. QUADEAU is designed to easily adapt to all type and size of project. The tool, encoded within an Excel spreadsheet, is intuitive and easy to use for most individuals without specific engineering knowledge.

Keywords: stormwater management, modelling and simulation tool, best management practices.
\end{abstract}




\section{Introduction}

Climate projections indicate that heavy precipitation events are likely to become more frequent. The growing cities sealing rate generates more and more runoff that causes extensive damage. The urbanization is responsible for the tremendous disruption of the natural water cycle observed in most cities.

Best Management Practices (BMPs) can increase the resiliency of stormwater management to a changing climate. A large array of BMPs is available but their efficiency evaluation requires modelling tools.

Several models are already available to assess the effectiveness of BMPs in the urban environment. These models allow designers to evaluate and compare different sustainable stormwater management scenarios in order to meet mandatory or voluntary performance standards. These models are designed to predict environmental outcomes as water quality, water flow quantity, streamflow, groundwater recharge... Models are designed to be effective in a specific territory scale: a single site, a neighbourhood, a watershed, a city. They also need lot of data on these specific sites.

Other simple models exist and require relatively limited input data and no strong technical expertise. Among these models, the EPA National Stormwater Calculator [1] estimates the volume and frequency of runoff from a selected site based on local soil, topography, climate data, land cover and BMP data. The Werf BMP Select Model [2] is intended for project ranging from the site scale up to the watershed scale. This model requires inputs data as hourly precipitation, land use distribution and BMP parameters in order to estimate the runoff volume, the pollutant loads and the costs.

The "QUADEAU" tool, developed for Brussels Environment, is an easy to use tool designed to be effective whatever the scale of the projected public space located anywhere within the Brussels-Capital Region (BCR). Focused on runoff volume reduction, the QUADEAU tool enables a designer to examine the effectiveness of alternative scenarios for controlling stormwater.

Comparatively to other tools, QUADEAU models any public space in an original way by the identification of two types of surfaces (tributary or collecting), by relations with the surrounding areas (private parcels or other public spaces) and with the integration of different outlet.

QUADEAU is also distinguished from other tools thanks to the possible optimization of a large number of parameters specific to each technique.

\section{General overview and objectives}

The development of the QUADEAU tool follows two major goals. The first objective of the tool is to assess the hydrological efficiency of a public project designed with BMP by giving the amount of stormwater manage by the BMP that do not reach the outlet.

Secondly, by the assessment and design of BMP, QUADEAU promotes the integration of BMPs in the public space. This alternative stormwater 
management to pipes system fosters the creation of a surface rain water sewer system.

To reach these two objectives, the model takes into account simple inputs data on the local hydrogeology, the characteristics of the urban surfaces and the type of BMP. A project is modelled in the tool by creating flow networks between different areas of the project. It estimates the amount and flow of stormwater that percolates throughout the soil, evapo(transpi)rates, accumulates into BMP and finally flows into the downstream reaching mandatory or voluntary hydraulic objectives.

QUADEAU is a desktop application tool structured in seven modules and includes ten Excel spreadsheets (see Figure 1). Seven informative sheets, directly accessible to the user of the tool, are attached to the tool to facilitate its use.

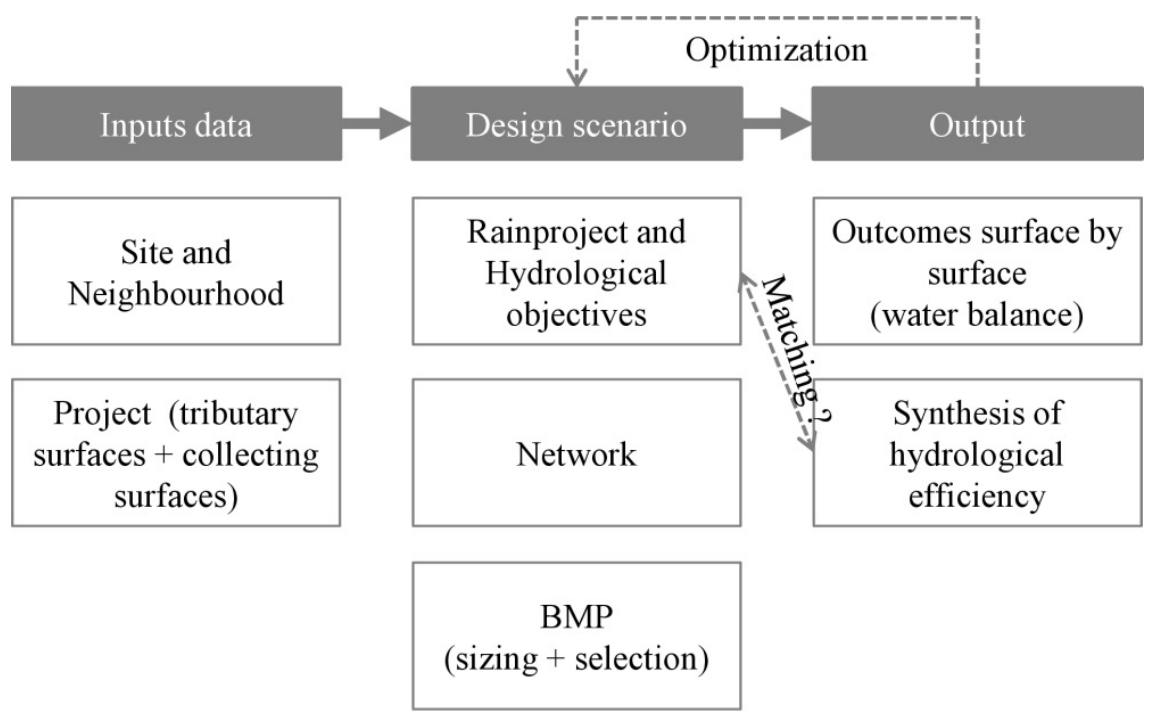

Figure 1: $\quad$ Structure of the tool divided in 7 modules.

\section{Modelling components of QUADEAU}

The QUADEAU tool focuses on limiting the extent and the complexity of input data relative to the neighbourhood and the site. The designer introduces his project with the inputs data and the location of the projected public space in the surrounding neighbourhood. Then he models the stormwater management designed scenario and finally receives a synthesis of the hydrological efficiency of his project. If the output data do not match the hydrological threshold objectives of the project, the designer is invited to optimize his designed scenario by changing one parameter (see Figure 2). 


\subsection{Inputs data}

\subsubsection{Site and neighbourhood module}

Three main characteristics of a site project have to be mentioned before modelling:

- The impervious soil rate

- The nature of the project (new or renovation)

- The potential of infiltration

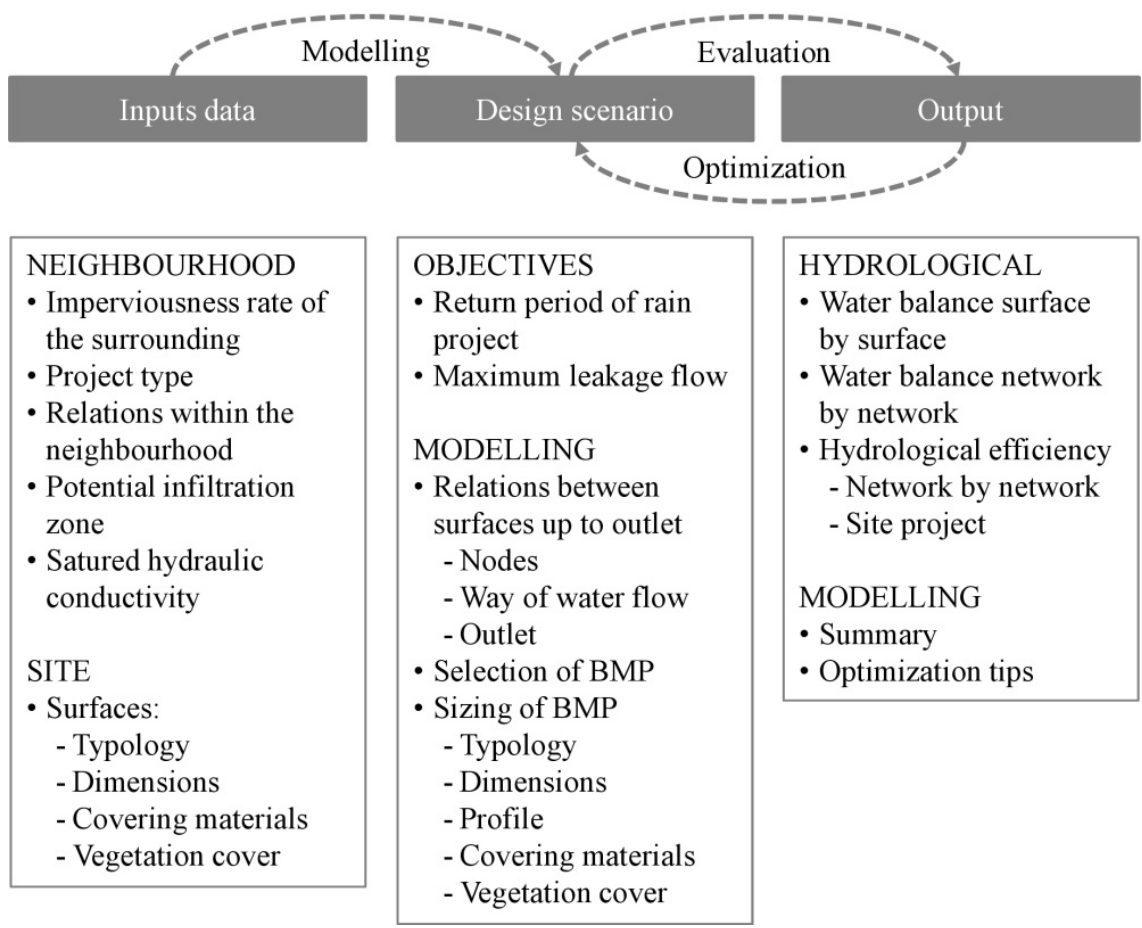

Figure 2: $\quad$ Summary of the modelling, evaluation and optimization processes of the QUADEAU tool.

A project is introduced in the tool by giving the territorial location within the Brussels-Capital Region (BCR) of the projected public space. This information is used to access a soil regional database giving the imperviousness rate of the surrounding sites. This data is used to determine the space constraints on the project. A project located in densely urbanized areas will be more difficult to be expected because of the existing infrastructures and buildings in the neighbourhood.

The tool is designed to be effective for both new or renovation public space project. Objectives will be more severe for new construction projects than for renovation ones and adapted to the soil infiltration rate. 
A map produced by De Bondt and Claeys [3] and directly available from the tool is used to identify the potential infiltration areas within the Brussels region according to the soil permeability, the local hydrogeology, the slope and the protection zone of groundwater pumping.

Three different potential infiltration zones are specified to characterize the physical and infiltration potential of a site:

- Zone A: rainwater infiltration is difficult or impossible or not required

- Zone B: rainwater infiltration recommended by surface infrastructures (swales, bioretention, rain garden, ...)

- Zone C: rainwater infiltration recommended by surface and/or deeper infrastructures (trenches, pits).

User has to select one of these zones corresponding to his site location.

In order to identify the specific site soil infiltration rate, user also has to undergo a percolation test (MDDEP [4]) allowing to know the saturated hydraulic conductivity.

If the saturated hydraulic conductivity $\mathrm{k}_{\mathrm{S}}$ is above $20 \mathrm{~mm} / \mathrm{h}$ and groundwater is more than 1 meter deep, superficial infiltration practices may be built. If the site is located within zone $\mathrm{C}$, the tool proposes to test the underground (up to $3 \mathrm{~m}$ deep) to eventually find more permeable geological formations.

To locate the public space site within the neighbourhood, user specifies the site relationships with two different objects: upstream produced by public spaces and by roofs of surrounding buildings.

Stormwater streaming down upstream public spaces and roofs of surrounding buildings may flow to the site giving the project a large amount of water that have to be manage on the site.

The tool allows designer to relate the site to many upstream public spaces and roofs of surrounding buildings by introducing the chronicle water flow of these objects as inputs data.

A chronicle water flow is the amount of water flowing out a surface each 5 minutes during the four hours rain.

Where the chronicles water flows are unknown, the tool estimates the amount of water coming from these upstream public spaces and these roofs based on their area and their covering materials.

\subsubsection{Project module}

Modelling a project within the QUADEAU tool asks the designer to define two types of nodes of the network:

- The relations between the site and the neighbourhood.

- The surfaces of the project.

The relationships between the site and the neighbourhood are of two types (see point 3.1.1 here above):

- Relation with upstream public spaces.

- Relation with roofs of surrounding buildings.

A site project is modelled in the tool by identifying two types of surface:

- Tributary surfaces.

- Collecting surfaces. 
Tributary surfaces in the site generate water flow during the rain. If their covering materials are porous and that the infiltration is possible $\left(\mathrm{k}_{\mathrm{S}} \geq 20 \mathrm{~mm} / \mathrm{h}\right)$, they may infiltrate much water but their first function is the runoff. Tributary surfaces are of 4 types:

- Collective or public space (e.g.: street, sidewalk...)

- Rear area (e.g.: driveway parking, small gardens...)

- Flat roof (e.g.: extensive green roof, intensive green roof)

- Sloped roof.

Each tributary surface is identified in the tool by its dimensions, its covering material and its vegetation cover. The tool automatically selects in a database the runoff coefficient corresponding to the covering material chosen by the user for the tributary surface that will be used for the calculation of the water balance of the surface.

With the exception of tributary surfaces flat roof type, tributary surfaces do not store volume during the rain.

Collecting surfaces collects water from surrounding surfaces during the rain and evacuate the stocked water by infiltration, evaporation and with controlled outflow to the outlet after the rain. Collecting surfaces are the place where BMP techniques will be inserted in the project. Collecting surfaces are identified in the tool by its dimensions and its BMP technique choice. A BMP technique is assigned to each collecting surface.

\subsection{Design scenario}

A design scenario summarised in Figure 2 is modelled and composed of three elements:

- the hydrological objectives

- the network flow

- the BMP techniques

These elements are the key parameters to design modelling optimization. Designer can at any time in the modelling process adjust one of these parameters in order to optimize its design.

Where the design does not match the hydrological objectives at the end of the modelling process, the designer is advised to modify one of these three elements.

\subsubsection{Design rain project and hydrological objectives module}

Based on observed precipitation, the Royal Meteorological Institute of Belgium (RMI) establishes tables that allow gathering precipitation events according to their probability of occurrence frequency.

Institutes involved in stormwater management in the BCR are used to build a theoretical rain event called "design rain project". In the BCR, the typical design rain project lasts 4 hours and is constructed from the middle by successive time increments of 5 minutes and its peak intensity occurs after 120 minutes. The resulting curves are symmetrical and their peak intensity depends on the duration of occurrence frequency, called return period. 
The choice of a return period of a design rain project is always accompanied by a maximum leakage flow of the site to the outlet. The leakage flow is the flow rate, expressed in liters per second per hectare, which flows out of the site to the outlet.

The hydrological objectives both applied to a site project are:

- The return period of a design rain project

- The maximum leakage flow

This couple of objectives is determined in function of the three main criteria mentioned in the site and neighbourhood module:

- The total imperviousness of the neighbourhood: if the neighbourhood is poorly built, it should be easier to set up BMP techniques; objectives are more severe if the imperviousness is low.

- The type of project: objectives are less severe for a renovation project

- The local hydrogeology: (map of potential infiltration zones and the measured saturated hydraulic conductivity). For impervious soil, it is recommended to slow runoff for exceptional rain (return period $\geq 10$ years). For pervious soil, in addition to the slowdown of exceptional rainfall, it is recommended to infiltrate water for current rain (return period $<10$ years).

QUADEAU offers the opportunity to choose mandatory or voluntary couple of objectives corresponding to the reality of the project: designer can be more or less demanding with respect to the performance objectives.

\subsubsection{Network module}

Networks are identified in the tool by the selection of a unique outlet. User has to select one outlet by network among sewer, territorial water system, expanse of water, downstream public space. The designer has the opportunity to elaborate and model four different networks for each project.

Networks are composed by nodes of three types (relations with the neighbourhood, surfaces and outlet) and by the ways of water flow. By modelling convention:

- relations with the neighbourhood may flow to tributary or collecting surface.

- tributary surface may flow to another tributary surface or collecting surface.

- collecting surface may flow to another collecting surface or reach the outlet.

According to the design rain project, once the relations between the nodes of the networks are configured and before the selection of BMP techniques, the tool provides the water balance for each network. The water balance represents the amount of precipitated water, the maximum flow volume at the outlet, the potential infiltrated volume, the potential volume of surface detention and the need for storage volume during the rain for each network.

\subsubsection{BMP module}

One BMP technique has to be selected for each collecting surface of the project. The choice of a technique among the others behoves to the designer but the tool may orientate the choice. Indeed, with references to Azzout et al. [5] and 
MDDEP [4], the tool operates a first BMP selection for each collecting surfaces based on four criteria (see Figure 3). Designer responds to those criteria according to his project.

\begin{tabular}{|l|} 
Site constraints \\
\begin{tabular}{|l|}
\hline - Soil is not conducive \\
to the presence of \\
water \\
- Vulnerable \\
groundwater \\
- Bad absorption \\
capacity \\
- Water charge polluant \\
- Shallow groundwater \\
- No outlet \\
- Bad load-bearing \\
capacity \\
- Steep site \\
- Little land space \\
\hline
\end{tabular}
\end{tabular}

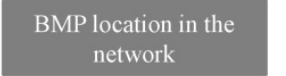
- Pretreatment technique
- Technique located at the source
- Water management in movement (transport management)
- Technique as an outlet

Major BMP hydrological principle

\begin{tabular}{|l|}
\hline Technique managing \\
water primarily by \\
- Infiltration \\
- Evaporation \\
- Storage \\
- Water flow control \\
\hline
\end{tabular}

BMP environmental potentialities

\begin{tabular}{|l|}
\hline Technique provides \\
advantages as: \\
- Groundwater \\
recharge \\
- Feeding vegetation \\
- Contribution to a blue \\
frame \\
- Contribution to a \\
green frame \\
- Multyfunctionality \\
\hline
\end{tabular}

Figure 3: $\quad$ BMPs selection criteria.

The stormwater BMP that can be simulated in the model include swale, permeable pavement, stormwater trees, infiltration basin, dry basin, water basin, bioretention, rain garden, drainage trench, infiltration pit. For each BMP, the tool offers the designer the possibility to adjust some specific parameters in order to correctly model the project. Specific adjustable BMP parameters concern the typology, the dimensions, the profile, the covering materials and the vegetation cover. These parameters are the key elements for a eventually optimization of the project.

\subsection{Outputs data}

\subsubsection{Outcomes surface by surface}

Depending on the design rain project, the water balance is calculated for each time increments of 5 minutes during the rainfall and for each surface. For all tributary surfaces, the tool calculates the amount of precipitated water, the amount of injected water, the amount of intercepted water by the vegetation, the amount of infiltrated water, the amount of detention stored water and the amount of runoff water. For all collecting surfaces, the amount of water accumulated in the BMP technique is also calculated. The volume of injected water is the part of rainwater that flows from a surface to another, according to the defined network. As output, the tool provides an overview surface by surface of the water balance.

\subsubsection{Synthesis of hydrological efficiency}

At the end of the evaluation process, the tool summarises the major inputs data concerning the surrounding and the design of the site. 
Each network is also summarised with its potentialities of water balance. The synthesis of hydrological efficiency gives the designer the water balance for all networks during and after the rainfall.

The synthesis gives the total volume of water that is intercepted by the vegetation, percolates through the soil, accumulates in the best management practice techniques and finally flows into the outlet during the rain. The synthesis gives also the total volume of water that evaporates, percolates through the soil, flows into the outlet and the time for draining of structure after the rain.

Finally, the hydrological efficiency, i.e. the amount of water that reaches the outlet compared to the total precipitation according to the design rain project, is graphically produced.

\section{Discussion}

QUADEAU is a stormwater management tool developed for the BCR that highlights the potential of a sustainable approach of stormwater management. Promoting the integration of BMPs within the Brussels urban area, QUADEAU evaluates the impact of each public space project on the water cycle.

QUADEAU is encoded within an Excel spreadsheet, which means that it is intuitive and easy to use for most individuals without specific engineering knowledge. The low number of data to be entered in the tool allows comparing QUADEAU in its easy-going to those developed in North America. But how projects of public spaces are modelled in the tool distinguishes QUADEAU from other stormwater management tool. Despite this simplicity QUADEAU offers in an original way the opportunity to select and evaluate a large amount of specific parameters of BMPs and let the choice between mandatory or voluntary hydrological objectives is considered as an advantage.

QUADEAU is designed to be a support tool for designer accompanying preliminary design for its. QUADEAU is not a dimensioning tool that provides one solution to one project. With back and forth movements within the tool, QUADEAU allows to compare alternative BMP solutions for the project.

Although QUADEAU realizes a complete water balance for any project of public space, one particular emphasis for the future work will be to define how water quality can be integrated in the BMP modelling and design process.

Another development that could be made to the tool in the future concerns the connection between the private parcels and the public space. So far the tool works with global assumptions to estimate the total runoff from the private parcels which flows on public space. An update to the tool will include the ability to link to a specific stormwater management model for private parcels.

Finally, future development of the tool should include among the analysis already present, as the reduced runoff volume and ground water recharge, other environmental BMP benefits including carbon sequestration, reduced energy use and maintenance savings. 


\section{References}

[1] U.S. Environmental Protection Agency, EPA, "National Stormwater Calculator User's guide - Version 1.1", 2014, National Risk Management Research Laboratory, U.S. Environmental Protection Agency, Cincinnati, Ohio (http://www.epa.gov/nrmrl/wswrd/wq/models/swc/nrmrldev/swc/)

[2] Water Environment Research Foundation, WERF, "WERF BMP select model - Version 2.0", 2013, Alexandria, Virginia (http://www.werf.org)

[3] De Bondt, K. \& Claeys, P., Urban Hydrological Landscapes in Brussels (Belgium): What can Geosciences bring to stormwater management in cities, Landscape and Urban Planning, to be submitted, March 2014

[4] Ministère du Développement durable, de l'Environnement, et des Parcs, Ministère des Affaires municipales, des Régions et de l'Occupation du territoire, MDDEP, MAMROT, Guide de gestion des eaux pluviales Stratégies d'aménagement, principes de conception et pratiques de gestion optimales pour les réseaux de drainage en milieu urbain, 2012

[5] Azzout Y., Cres F.N., Barraud S., Alfaki E., 1994 Techniques alternatives en assainissement pluvial : choix, conception, réalisation et entretien Ed. Lavoisier, Paris, 372 pages 